\title{
Padre Antônio Vieira e o projeto colonial: uma análise da IV Parte do Sermão da Sexagésima
}

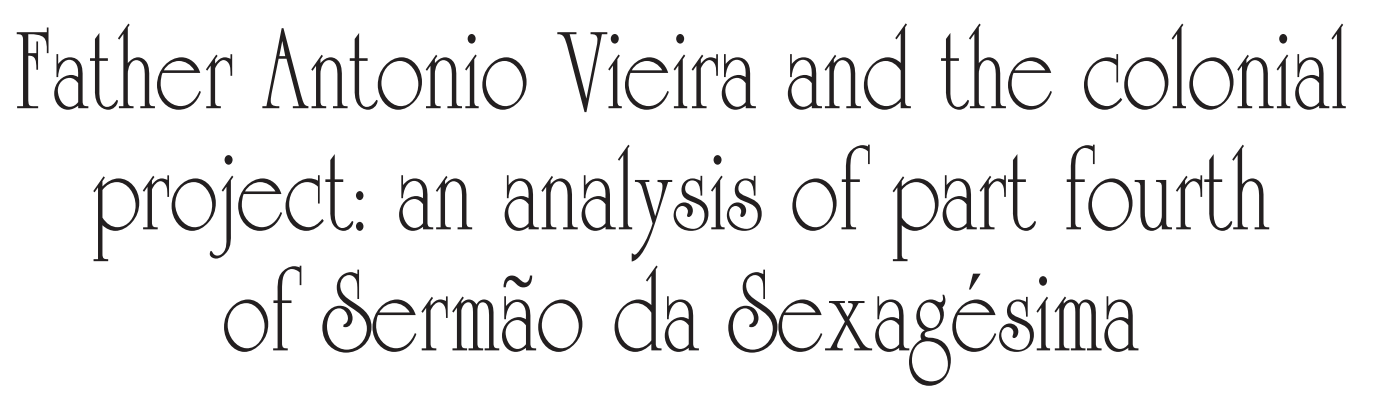

Ivanaldo Oliveira Santos*

Resumo: Esse estudo tem por objetivo realizar uma análise da quarta parte do Sermão da Sexagésima, Do Padre Antonio Vieira, tomando-se por base a Análise do Discurso Crítica desenvolvida por Noam Fairclough. Conclui-se afirmando que Antônio Vieira, em seu discurso, enfatiza a importância da coroa portuguesa investir na colonização do Brasil, pois, a partir desse investimento, Portugal seria enaltecido no contexto internacional, assegurando sua permanência no centro das decisões políticas mundiais. E se Portugal, uma nação católica, era o centro das decisões políticas, a Igreja, por conseguinte, seria o centro das decisões religiosas.

Palavras-chave: Antonio Vieira; Análise; Sermão da Sexagésima; Igreja; Colonização.

Abstract: This study aims at carrying out an analysis of fourth part of Sermão da Sexagésima, by Father Antonio Vieira, based on Critical

\footnotetext{
* Doutor em estudos da linguagem pela UFRN Filósofo, com pós-doutorado em estudos da linguagem pela USP, professor do Departamento de Filosofia e do Programa de Pós-Graduação em Letras da Universidade do Estado do Rio Grande do Norte (UERN). E-mail: ivanaldosantos@yahoo.com.br.
} 
Discourse Analysis developed by Noam Fairclough. We conclude by stating that Antonio Vieira, in his speech, emphasized the importance of the Portuguese crown to invest in Brazilian colonization, because from this investment, Portugal would be praised in the international context, ensuring their stay in the world of political decisions. And if Portugal, a Catholic nation, was the center of political decisions, the Church, therefore, would be the center of religious decisions.

Keywords: Antonio Vieira; Analysis; Sermão da Sexagésima; Church; Colonization.

\section{Introdução}

O Padre Antônio Vieira, sacerdote da Companhia de Jesus, cujos membros são popularmente conhecidos como jesuítas, foi um dos grandes líderes místicos e políticos do Brasil no século XVII. Em grande medida, ele foi um dos responsáveis pela colonização do Brasil por Portugal. No início do século XVII Portugal não demonstrava interesse em colonizar o Brasil. Coube a este padre conscientizar o rei e a coroa portuguesa da importância dessa colonização para o desenvolvimento de Portugal, da Igreja e, por conseguinte, da manutenção do pacto Igreja-Estado.

A oratória jesuítica do Padre Antônio Vieira apresenta um grandioso dinamismo. Seu discurso contemplou toda a problemática social do seu tempo. O dinamismo de Vieira levou-o a produzir um grande acervo de obras, dentre as quais merecem destaque os seus sermões, os quais foram originalmente organizados em 15 (quinze) volumes, 13 (treze) publicados entre 1679 e 1690, e 02 (dois) entre 1710 e 1718. Os sermões foram o resultado das relações discursivas do pregador no que diz respeito ao projeto colonial durante o século XVII.

O objetivo desse estudo é apenas analisar o discurso presente na IV parte do Sermão da Sexagésima. Para tanto, dividi-se em duas partes: a) Padre Antônio Vieira e o projeto colonial e b) Padre Antônio Vieira e o projeto colonial: uma análise do discurso da IV parte do Sermão da Sexagésima. 


\section{Padre Antônio Vieira e o projeto colonial}

Orador de porte internacional, Padre Antônio Vieira possuía um discurso poderoso composto de alegorias bíblico-cristãs e pensamento mercantil. Sua relação com o processo de colonização brasileira se deu pela sua presença na colônia, pois ele fazia parte da Companhia de Jesus, que veio para o Brasil trabalhar na evangelização do colono e do índio. Além disso, durante o período colonial, Antônio Vieira era conselheiro na corte portuguesa. Dessa forma, participava das decisões políticas referentes à administração da colônia, por essa razão participou ativamente da colonização da terra brasileira. O jesuíta desempenhou, no Brasil colônia, um "papel político-místico”. Político porque se preocupava em manter Portugal em posição privilegiada na disputa mercantilista europeia e mística porque se esforçava para evangelizar os nativos que habitavam o território da colônia brasileira.

A princípio pode-se dizer que o Padre Antônio Vieira se mostrava preocupado com o comodismo dos chefes políticos e religiosos da metrópole portuguesa mediante a ameaça da Espanha e da Holanda no tocante às estratégias mercantilistas ${ }^{2}$. Isto é, Portugal estava em posição favorável na corrida mercantilista, porém, corria o risco de ser alcançado pela concorrência da Espanha e da Holanda. Por isso, o pregador alertava a corte lusitana a ficar vigilante para não ser pega de surpresa. Acerca dessas afirmações escreve Bosi:

Como pregador da corte, o jesuíta [Antônio Vieira] tem acesso aos estratos do privilégio, mas a sua máquina oratória deve, paradoxal e temerária, investir contra as regalias e as isenções de que gozavam os nobres e os religiosos nessa fase de reerguimento do império duplamente ameaçado: pela Espanha, no xadrez europeu, pela Holanda, na estratégia atlântica e colonial. ${ }^{3}$

1 COSTA, J. B. A. P. F. O milenearismo nacionalista do Padre Antônio Vieira. Associação Civil Santa Maria das Vitórias: Anápolis, 2008, p. 1. Disponível em http://www.santamariadasvitorias.com.br. Acessado em 06/10/2009.

2 HERMAM, V. O Padre Antônio Vieira e os problemas econômicos do império português. In: Revista Eclesiástica Brasileira, fasc. 211, setembro, 1993, p. 574-575.

3 BOSI, A. Dialética da colonização. São Paulo: Companhia das Letras, 1995, p. 123. 
No século XVII, o Padre Antônio Vieira se esforçava, através do seu discurso, para persuadir a nobreza lusitana a explorar a terra brasileira, pois enquanto os portugueses achavam-se acomodados na metrópole, a concorrência, especialmente da Espanha e da Holanda, continuava investindo em suas conquistas marítimas. Além disso, a colônia era uma fonte de riquezas, por isso era necessário explorá-la.

O papel do Padre Antônio Vieira estava ligado à hegemonia política e comercial que Portugal desfrutava no século XVII. Como jesuíta, sua intenção era conciliar a missão colonizadora à salvífica, isto é, o missionário pretendia agir convenientemente, pois, com a colonização do Brasil, abria-se uma porta para se catequizar os nativos. É o que afirma Meksenas:

Não é possível ignorar, entretanto, que a obra de Vieira é condicionada ao momento que militava. Assim, sua definição de ação estava presa na aparente oposição entre missão salvífica (eminentemente religiosa) e missão colonizadora (eminentemente político-econômica). Não há como dissociá-las e ambas aparecem conciliadoras como prática catequética combinada com prática colonizadora ${ }^{4}$.

Pode-se conceituar o projeto colonial do Padre Antônio Vieira, como sendo um projeto político-místico. O pregador acreditava que Portugal era a nação eleita por Deus para levar a mensagem cristã às nações que ainda não professavam a religião católica, por isso via no Brasil a oportunidade de iniciar essa missão evangelizadora, pois, a colônia abrigava milhares de almas que ainda não tinham ouvido falar de Cristo. Com relação à eleição de Portugal, afirma Vieira:

[...] A primeira vocação da gentilidade foi nos dias de Herodes in diebus. Herodis regis - a segunda quando já se contava mil e quinhentos anos do nascimento de Cristo. A primeira foi por meio dos reis do Oriente: Ecce Magi aboriente Venerunt - a segunda por meio dos reis do Ocidente, e dos mais ocidentais de todos, que são os de todos, que são os de Portugal ${ }^{5}$.

4 MEKSENAS, P. Educação, política e militância no jesuíta Antônio Vieira. In: Revista Educação em Questão, maio/ago, 2007, p. 62.

5 Padre Antônio Vieira apud PÉCORA, A. Teatro do sacramento: a unidade teológico-retórico-política dos sermões de Antônio Vieira. São Paulo: UNICAMP, 1994, p. 245, itálicos no original. 
Neste sentido, o discurso produzido por Antônio Vieira é dirigido às bases da sociedade colonial (missionários católicos, índios, negros, colonos etc), mas é voltado, da forma como é descrita por Fairclough ${ }^{6}$, para as elites políticas do século XVII. Antônio Vieira produziu um discurso totalizante, ou seja, um discurso que integra os vários segmentos sociais. Entretanto, essa integração tinha como meta central os interesses políticos e religiosos da metrópole, de Portugal.

O discurso totalizante produzido por Antônio Vieira pode ser enquadrado no que Massini ${ }^{7}$ classifica como sendo o "poder terapêutico da palavra”. A palavra, o discurso, no Padre Vieira é terapêutica porque, simultaneamente, é portadora do sagrado, ela tem a missão de converter, evangelizar e santificar os povos gentios que estavam no Brasil colônia, mas também tinha a missão de construir uma civilização, uma missão política de conduzir a elite portuguesa e, por conseguinte, o Brasil colônia a dimensão de liderança dentro da sociedade ocidental do século XVII.

De acordo com a citação anterior, entende-se que Portugal é visto pelo Padre Antônio Vieira como o país missionário escolhido por Deus para levar a mensagem salvífica à população indígena que habitava na colônia. Isso mostra que ele defendia a catequização do índio. A sua missão na colônia seria desempenhar uma ação evangelizadora capaz de converter o nativo e agregá-lo ao reino cristão português.

Para realizar sua missão, o pregador teria que conscientizar a Igreja acerca da grande obra a ser realizada na colônia. Em alguns casos ele teve que denunciar a postura incoerente de alguns dos seus companheiros missionários que demonstravam certa ambiguidade ao lidarem com a questão da catequização indígena. É o que mostra Bosi:

A contradição de que Vieira se mostra bem consciente, e que o pungia com um remorso, espelha a condição ambígua da Igreja Colonial. Como poderia uma instituição, que vivia dentro do Estado

6 FAIRCLOUGH, N. Discurso e mudança social. Brasília: Editora da UNB, 2001.

7 MASSIMI, M. Dimensões pedagógicas e psicológicas da retórica segundo padre Antônio Vieira e a tradição jesuíta. In: Communio, Revista Internacional de Cultura, V. XXVIII, n. 3, jul./set. 2009, p. 878. 
monárquico, e à custa dos excedentes deste, desenvolver um projeto social coeso à revelia das forças que dominavam esse mesmo sistema? ${ }^{8}$

Há de se compreender que, se o Estado bancava a Igreja, essa por sua vez tinha a obrigação de se submeter às suas ordens, porém, o Padre Antônio Vieira não aceitava a ideia dos seus companheiros religiosos inverterem o papel que lhes era confiado, os quais, por conveniências e manobras políticas, em vez de defenderem o nativo da colônia, usavam de má fé e o entregavam aos colonos para ser submetido à escravidão.

Uma questão relevante referente ao Padre Antônio Vieira e ao projeto colonial, foi a maneira pela qual ele lidou com a mão de obra escrava no tocante aos negros africanos que substituíram os índios no trabalho pesado da colônia. O jesuíta entendia que o trabalho escravo do negro era um sacrifício compensador. 0 discurso segue a linha de pensamento que defende a opressão do africano como sendo algo providencial que resultaria em remissão para o mesmo. A engenhosidade de orador levou o Padre Antonio Vieira a construir um discurso objetivando uma ação estratégica favorável aos seus ideais místicos, um discurso que alcançaria todas as partes da sociedade colonial, ou seja, acalmaria os ânimos dos colonos, interromperia a captura dos índios, e, por fim, faria os negros aceitarem com tranquilidade o serviço escravo.

Vale ressaltar que para introduzir o negro na colônia, o Padre Antônio Vieira teve que formular argumentos para justificar tal ação, já que se colocava contra o trabalho escravo do índio. Porém como explicar tamanha contradição? Ora o jesuíta é contra a escravidão indígena, ora defende que se adote a escravidão negra no Brasil. 0 discurso parte do pressuposto de que a vinda dos escravos africanos para a colônia justificava-se pela necessidade que eles tinham de abraçar a fé católica. Dessa forma, a vinda dos negros para o Brasil teria sido plano de Deus, com o propósito de torná-los cristãos. Conforme afirma Bosi:

$8 \quad$ BOSI, A. Dialética da colonização. op., cit, p. 137. 
Dirigindo-se a irmandade dos Pretos, em 1633, na Bahia, afirma-lhes: "deveis dar infinitas graças à Deus por vos ter dado conhecimento e por vos ter tirado de vossas terras, onde vossos pais e avós vivíeis como gentios, e vos ter trazido a esta onde instruídos na Fé, vivais como Cristãos e vos salveis”. [...] a expansão da fé Cristã justificava, aos olhos do orador, a escravidão9 .

O jesuíta era consciente que não seria possível colonizar o Brasil sem a presença da mão de obra escrava, então, se não fosse a do índio teria que ser outra, aí entra o papel do negro na colônia, que era o de ocupar o lugar do índio no trabalho pesado.

O Padre Antônio Vieira tinha a missão de evangelizar os nativos, obter lucros para a coroa portuguesa, instruir a nação cristã e ampliar a evangelização às demais nações ainda não alcançadas pela Igreja. E para alcançar esses objetivos, ele precisava manter o ambiente colonial estável para que se atingissem resultados satisfatórios ao desenvolvimento da colônia. Assim sendo, Antônio Vieira exerceu, na colônia, uma função político-mística e seu discurso oscilava para ambos os lados da balança que equilibrava o desenrolar da colonização brasileira. Neste sentido, o discurso desse religioso era um modo de ação, de prática política, que pretendia provocar um modo de agir em seu ouvinte (rei, coroa portuguesa, colono, índio e negro), uma vez que um "discurso como prática política estabelece, mantém e transforma as relações de poder e as entidades coletivas (classes, blocos, comunidades, grupos) entre as quais existem relações de poder" 10 .

O sacerdote teve que se esforçar para desempenhar dois papéis: o de estrategista político e o de religioso. Ambos seriam de suprema importância à harmonia na colônia. Com relação à última informação, demonstra Pécora:

No interior da variedade distendida sob os estudos de Vieira, passa-se com ligeireza do acento beletrista para o de político hábil, oportunista, maquiavélico [...]. Mas essa é apenas uma imagem. Daí recua-se um ou dois passos e recolhe-se outra bem diversa: A imagem de um Antônio Vieira "Apóstolo do Brasil”, um Vieira

9 BOSI, A. Dialética da colonização. op., cit, p. 199.

10 FAIRCLOUGH, N. Discurso e mudança social. op., cit, p. 94. 
missionário, despojado a ponto de doar sua cama aos doentes ou o rendimento da publicação dos seus sermões à dotação de missões, $[\ldots] .{ }^{11}$.

A razão pela qual o Padre Antônio Vieira oscilava entre a imagem do político e a do religioso era porque, na colônia, ele convivia com três realidades distintas: 1) os portugueses que eram os exploradores; 2) os índios que eram escravizados, porém, precisavam de catequese; e 3) os negros que mais tarde são colocados na condição de escravos. Em síntese, na sociedade colonial, o jesuíta estaria em contato com três mundos: o do português, o do índio e o do negro. É por essa condição que seu discurso ora avança, ora recua, pois o sucesso de seus propósitos dependia da harmonia desses mundos. Isto é, para catequizar o índio ele precisava do apoio dos portugueses; para que o indígena estivesse livre para ser catequizado teria de ser escravo e, para este se livrar da escravidão, precisaria ser substituído por outro, no caso o negro.

O Padre Antônio Vieira se esforçava para atingir seus objetivos missionários, para isso teria que exortar a coroa portuguesa a seguir o reto caminho cristão, o que resultou em conflitos com os colonos e consequentemente com o reino de Portugal. Por mais que o jesuíta se afastasse das questões religiosas referentes à catequização do indígena continuava ligado a elas, pois seu objetivo norteador era trazer o indígena às escolas jesuíticas, a fim de ampliar a conversão deste ao cristianismo.

O discurso do Padre Antônio Vieira revolucionou o período colonial, uma vez que "o pregador empreendeu uma ação político-mística que envolveu todas as camadas sociais da era colonial"12. Seu discurso teve origem na Europa, quando projetou a colonização brasileira, avançou pela colônia, nas questões referentes à catequização, e, por fim, desaguou na colônia, no Brasil, com seus respectivos problemas relacionados.

11 PÉCORA, A. Teatro do sacramento: a unidade teológico-retórico-política dos sermões de Antônio Vieira. op., cit, p. 47.

12 HERMAM, V. O Padre Antônio Vieira e os problemas econômicos do império português. op., cit, p. 583. 
Enfim, o projeto colonial de Vieira consistia, no século XVII, em conscientizar Portugal da sua missão de evangelizar as nações bárbaras desconhecedoras da mensagem cristã, começando pelo Brasil com sua imensa população indígena, continuando com os negros vindos da África, estendendo-se, por fim, aos demais povos que faziam parte da gentilidade da época. Assim, Portugal tornar-se-ia uma potência político-econômica no contexto do século XVII.

O amplo discurso do Padre Antônio Vieira, referente à sua relação com o ambiente colonial, resultou na produção de um grande acervo de obras. O pregador escreveu mais de quinhentas cartas, obras de profecias, mas o que o consagrou foram os seus sermões, nos quais o jesuíta concentrou o melhor do seu talento e saber. Foram esses sermões que tornaram o Padre Antônio Vieira a estrela de primeira grandeza do barroco luso-brasileiro.

É preciso ressaltar que o discurso do pregador demonstra a busca do entrelaçamento entre o Estado e a Igreja. Antônio Vieira enaltece a nação portuguesa. Para ele, Portugal recebe de Deus o privilégio de levar o cristianismo às nações descrentes. Desse modo, os sermões do Padre Antônio Vieira têm um caráter profético, já que o sermonista preocupa-se com o futuro político dos lusitanos. Seguindo esse mesmo raciocínio, Bosi, falando a respeito de Antônio Vieira, afirma que "no seu espírito verdadeiramente barroco fermentavam as ilusões do estabelecimento de um império luso e católico, respeitado por todo o mundo e servido pelo zelo do rei, da nobreza, do clero"13. É um momento onde essa ilusão ou sonho fica bastante evidente é a IV parte do Sermão da Sexagésima, a qual será alvo de uma análise.

\section{Padre Antônio Vieira e o projeto colonial: uma análise do discurso da IV parte do Sermão da Sexagésima}

O Sermão da Sexagésima foi proferido pelo padre Antônio Vieira na capela real em Lisboa, Portugal, no ano de 1655. A capela real era o

13 BOSI, A. História concisa da literatura brasileira. 32 ed. São Paulo: Cultrix, 1994, p. 44. 
lugar onde se realizavam as reuniões religiosas do Reino e ali estavam presentes todo o alto clero e as autoridades políticas da corte portuguesa. A Sexagésima, no calendário litúrgico da Igreja Católica em uso até o Concílio Vaticano II (1962-1965), era o segundo domingo antes do primeiro da Quaresma, aproximadamente 60 dias antes da Páscoa.

Padre Antônio Vieira inicia o referido sermão comparando a palavra de Deus à semente que é lançada ao campo, pois tem como base a parábola do semeador, do capítulo 8 do evangelho de São Lucas. 0 sermão está dividido em dez partes. Na primeira parte, Antônio Vieira faz distinção entre sair para semear e semear sem sair. Na segunda parte, o pregador faz indagações referentes aos efeitos da palavra sobre os ouvintes, ou seja, se a palavra de Deus é poderosa, por que não converte aqueles que a ouvem? Na parte III da Sexagésima, o seu autor enumera três possibilidades que justificariam a não conversão dos ouvintes da palavra anunciada: o problema deveria ser da parte do pregador, do ouvinte, ou do próprio Deus. Na parte IV do Sermão, a qual será o objeto de análise deste artigo, Padre Antônio Vieira aponta a diferença entre o pregador que teoriza e o que pratica a ação. Na parte V do Sermão da Sexagésima, Padre Antônio Vieira leva seu auditório a refletir acerca do estilo dos pregadores. O pregador exorta no item VI do sermão que a pregação deverá ter um só assunto, uma só matéria. Quando o leitor entra na parte VII vai perceber que Padre Antônio Vieira aconselha que os pregadores devam ter uma boa formação intelectual, de modo que preguem do seu e não do alheio. Nas três últimas partes do Sermão, o pregador conclui que a palavra pregada se torna ineficaz porque aqueles que pregam fazem isso para agradar os ouvintes, isto é, os pregadores não semeiam a palavra de Deus e sim de homens.

Retornaremos agora a IV parte do Sermão da Sexagésima, justamente o epicentro desse artigo. A parte IV do sermão em estudo é dedicada a mostrar aquilo que compõe a ação da pregação. O sucesso ou o fracasso de uma pregação resultam de um erro que o pregador possa vir a cometer, isto é, o problema da palavra de Deus não frutificar está nos pregadores. Na IV parte do Sermão da Sexagésima, Padre Antônio Vieira explica porque os pregadores são culpados pela não frutificação da palavra de Deus. Por isso, antes de iniciar a análise da 
parte IV do Sermão da Sexagésima, é necessário voltar à parte III do mesmo sermão, onde o pregador culpa seus companheiros religiosos pelo fracasso de suas pregações, e, especificamente pela ineficácia da palavra de Deus. Em suas palavras:

Quando o semeador do céu deixou o campo, saindo deste mundo, as pedras se quebraram para lhe fazerem aclamações, e os espinhos se teceram para lhe fazerem coroa. E se a palavra de Deus até dos espinhos e das pedras triunfa; se a palavra de Deus até nas pedras, até nos espinhos nasce; não triunfar dos alvedrios hoje a palavra de Deus, nem nascer nos corações, não é por culpa, nem por indisposição dos ouvintes. [...]. E assim é. Sabeis, cristãos, porque não faz fruto a palavra de Deus? Por culpa dos pregadores. ${ }^{14}$

Neste trecho, ele faz um discurso afirmando que se a pregação religiosa não está obtendo os resultados esperados é porque os pregadores não estão agindo como determina a tradição cristã. Em grande medida esse discurso funciona como introdução à IV parte da Sexagésima.

Na IV parte do Sermão da Sexagésima, está o ponto central do discurso do Padre Antônio Vieira. Nesta parte o pregador exorta Portugal a desempenhar um projeto político-místico a partir da colonização brasileira, pois defendia que a nação lusitana tinha a missão de levar o evangelho a todos os povos da terra e com isso contribuir com o engrandecimento do reino português. Essa parte oscila entre a pregação mística, própria de um sacerdote católico, e a construção de um projeto político para Portugal. Entretanto, essa oscilação é posta, a partir do discurso cristão, o qual afirma que é preciso levar Cristo a todas as pessoas. Segundo Vieira:

O pregador evangélico será pago não só pelo que semeia como pelas distâncias que percorre, e não volta nem mesmo diante das dificuldades que a natureza lhe apresenta: as pedras, os espinhos, as aves, o homem. Cristo ordenou que se pregasse a todas as criaturas [...]. ${ }^{15}$

14 VIEIRA, A. Sermões. V. 1. Erechin: Edelbra, 1998, p. 35.

15 VIEIRA, A. Sermões. V. 1. op., cit, p. 27. 
Então, de acordo com a referida citação, compreendemos que o projeto do Padre Antônio Vieira se dá a partir da concepção de se levar o cristianismo a todas as nações do mundo, e, por conseguinte, Portugal teria sido incumbido dessa missão pelo próprio Deus. Nesta perspectiva, há um discurso místico. Todavia, para a implantação desse projeto eram "necessárias ações de cunho político, tais como: transferência da população para a colônia, construção de estradas e cidades, construção de uma estrutura administrativa (governo geral, policiamento, coleta de lixo, correio etc)"16.

Dando continuidade a análise, observa-se que o Padre Antônio Vieira define o pregador pela vida e o exemplo, isto é, ele faz distinção entre o que teoriza e o que pratica a ação de pregar. Vejamos a citação:

Será porventura o não fazer fruto hoje a palavra de Deus, pela circunstância da pessoa? Será porque antigamente os pregadores eram santos, eram varões apostólicos e exemplares, e hoje os pregadores são eu e outros como eu? Boa razão é esta. A definição do pregador é a vida e o exemplo. Por isso, Cristo no evangelho não comparou ao semeador, senão ao que semeia. Reparai, não diz Cristo: Saiu a semear o semeador, senão, saiu a semear o que semeia [...]. Entre o semeador e o que semeia há muita diferença [...]. O semeador e o pregador é nome, o que semeia é o que prega, é ação, e as ações são as que dão o ser ao pregador. Ter nome de pregador ou ser pregador de nome, não importa nada; as ações, a vida, o exemplo, as obras, são as que convertem o mundo. ${ }^{17}$

Com base na citação, Padre Antônio Vieira afirma que a maior pregação é a ação, dando a entender que não há frutificação ou conversão porque os pregadores não vivenciam o que pregam. O orador estabelece na IV parte do Sermão da Sexagésima a dicotomia de um pregar, que é falar, e de um pregar, que é fazer. O citado padre aposta que a palavra só tem poder quando é acompanhada de ação. O jesuíta afirma que para converter o mundo é preciso mais do que palavras, tem que se honrar o título de pregador, pois o nome não significa nada se não se pratica ou exerce a função para qual é comissionado.

16 COSTA, J. B. A. P. F. O milenearismo nacionalista do Padre Antônio Vieira. op., cit, p. 2.

17 VIEIRA, A. Sermões. V. 1. op., cit, p. 36. 
Em síntese, o orador declara que a palavra importante é aquela que se torna ação, ou seja, indiretamente ele se referia às ações políticas que Portugal deveria executar para cumprir a missão estabelecida por Deus. É preciso observar que ele está discursando para uma plateia que, em grande medida, compreendia as alegorias bíblicas e também as metáforas políticas contidas em seu discurso. A corte portuguesa, reunida na capela real, compreendia que o Padre Antônio Vieira estava afirmando que os portugueses teriam que ser verdadeiros desbravadores para poder conquistar os povos não cristãos. Para tanto, teriam que abrir estradas, fundar povoados e, por fim, se instalarem na colônia.

Avançando um pouco mais na nossa análise, observamos que o Padre Antônio Vieira insiste na ideia de que os pregadores devam praticar aquilo que teorizam:

Uma coisa é o pregador e outra o que prega. 0 semeador e o pregador é nome; o que semeia e o que prega é ação; e as ações são as que dão o ser ao pregador. Ter o nome de pregador, ou ser pregador de nome, não importa nada; as ações, a vida, o exemplo, as obras, são as que convertem o mundo. 0 melhor conceito que o pregador leva ao púlpito, qual cuidais que é? O conceito que da sua vida têm os ouvintes. ${ }^{18}$

Na citação Padre Antônio Vieira deixa claro que para mover o coração dos homens a pregação deve ser acompanhada de obras. Quando o jesuíta difere entre falar ao vento e falar ao coração, ele quer dizer que uma coisa é pregar por pregar e outra coisa é pregar com empenho e compromisso no tocante à postura do pregador com relação a quem ouve, porque o ouvinte analisa a pregação com os ouvidos e com os olhos. Nesta parte, ele está construindo um discurso religioso e não propriamente político. Conforme mostra a seguinte citação:

Sabem, padres pregadores, por que fazem pouco abalo os nossos sermões? Porque não pregamos aos olhos, pregamos só aos ouvidos. Por que convertia o Batista tantos pecadores? Porque assim como as suas palavras pregavam aos ouvidos, o seu exemplo pregava aos olhos. ${ }^{19}$

18 VIEIRA, A. Sermões. V. 1. op., cit, p. 36.

19 VIEIRA, A. Sermões. V. 1. op., cit, p. 38. 
Continuando na perspectiva mística o Padre Antônio Vieira critica o cinismo dos pregadores que pregavam a palavra de Deus, mas suas vidas não condiziam com aquilo que pregavam. Na visão do Padre, eles falavam de penitência, mas não eram penitentes, pregavam sobre o jejum, porém não o praticavam, falavam de composição e modéstia, no entanto, estavam longe disso, enfim viviam uma verdadeira hipocrisia religiosa, eram pregadores de teorias, todavia suas obras os denunciavam. Nestes termos, é preciso observar o trecho a seguir:

As palavras do Batista pregavam penitência: Agite poenitention; Homens fazei penitência (Mt 3, 2) e o exemplo clamava: Ecce homo; eis aqui está o homem que é o retrato da penitência e da aspereza. As palavras do Batista pregavam jejum e repreendiam os regalos e demasias da gula, e o exemplo clamava: Ecce homo: eis aqui está o homem que se sustenta de gafanhotos e mel silvestre. As palavras do Batista pregavam composição e modéstia, e condenavam a solva e a vaidade das galas, e o exemplo clamava: Ecce homo; eis aqui está o homem vestido de peles de camelo, com as cerdas e silício à raiz da carne. As palavras do Batista pregavam despegos e retiros do mundo, e fugir das ocasiões e dos homens, o exemplo clamava: Ecce homo; eis aqui o homem que deixou as cortes e as cidades e vive no deserto e numa cava. Se os ouvintes ouvem uma coisa e vêem outra, como se hão de converter? ${ }^{20}$

É preciso notar que na citação supracitada o pregador, ao mesmo tempo em que critica seus companheiros eclesiásticos, chama a atenção do auditório para sua pessoa. Padre Antônio Vieira, que se dispusera a deixar o conforto da metrópole em Portugal, para executar seu projeto místico-político e também o da Companhia de Jesus, agora se achava impedido de dar continuidade à missão que lhe foi confiada, devido os colonos terem-no impedido, por se sentirem ameaçados de perder seus índios escravizados para a Companhia de Jesus e assim, não conseguirem lidar com a terra e, por conseguinte, o processo de colonização não teria avanço satisfatório. Nesta parte do discurso, fica patente a visão místico-político de Antônio Vieira para a colônia. De um lado, ele deveria ser o anunciador da mensagem cristã para

20 VIEIRA, A. Sermões. V. 1. op., cit, p. 38. 
os índios e os colonos. Do outro lado, ele deveria ser o arauto do desenvolvimento econômico e administrativo da colônia. Se o Brasil prosperasse, Portugal, que era a metrópole, também prosperaria.

No final da IV parte do Sermão da Sexagésima, Padre Antônio Vieira deixa claro o que lhe motiva a deixar Portugal e ir para a colônia habitada tanto por portugueses como também pelos índios:

Muito boa e muito forte razão era esta de não fazer fruto a palavra de Deus, mas tem contra si o exemplo e experiência de Jonas (Jon. 1.2-4). Jonas, fugitivo de Deus, desobediente, contumaz, e ainda depois de engolido e vomitado, iracundo, impaciente, pouco criativo, pouco misericordioso, e mais zeloso e amigo da própria estimação que da honra de Deus e salvação das almas, desejoso de ver sovertida a Nínive, e de a ver soverter com seus olhos, havendo nela tantos mil inocentes. Contudo, este mesmo homem com um sermão converteu o maior rei, a maior corte e o maior reino do mundo, e não de homens fiéis, senão de gentes idólatras. Outra é logo a causa que buscamos. Qual será? ${ }^{21}$

A citação mostra que o Padre Antônio Vieira compara os pregadores da corte ao profeta Jonas, mencionado nas escrituras sagradas. Diz o texto bíblico, que Jonas recebeu a missão de pregar aos habitantes de Nínive, dizendo que, se não se arrependessem e se convertessem, a cidade seria destruída, porém, o pregador não fez acaso da ordem de Deus, porque achava que aquelas pessoas não mereciam perdão e deveriam ser castigadas. No entanto, após ser convencidos por Deus, voltou atrás, e a mensagem do sermão preferido por ele converteu todas as almas daquela cidade. Significa dizer que o sermonista adverte a coroa portuguesa a não ser negligente, isto é, Portugal fora eleito por Deus para levar a fé cristã ao mundo e, dessa forma, seria conhecido como nação soberana. Então, se percebe que o pregador "via na colonização a chance dos lusitanos serem apresentados ao mundo como o povo bem-aventurado e abençoado por Deus" ${ }^{22}$. Enfim, como os líderes portugueses negligenciavam essa oportunidade de tornarem o reino

21 VIEIRA, A. Sermões. V. 1. op., cit, p. 38.

22 HERMAM, V. O Padre Antônio Vieira e os problemas econômicos do império português. op., cit, p. 594. 
português conhecido e destacado das demais nações desenvolvidas no século XVII, especialmente Espanha e Holanda, Padre Antônio Vieira alerta-os a lutarem por essa causa. É o que mostra a pergunta que encerra a parte do sermão em análise: "Outra é logo a causa que buscamos. Qual será?”23. A causa que ele se refere é justamente Portugal ser, no século VII, uma potência político-econômica.

\section{Conclusão}

O discurso do Padre Antônio Vieira, presente na IV Sermão da Sexagésima, utiliza argumentos que influenciaram o meio social, especificamente a coroa portuguesa no século XVII. Essa influência se dá por meio da pregação da mudança de estratégia política, ou seja, era preciso que Portugal se interessasse pelo desenvolvimento econômico e administrativo da colônia e, com isso, tomasse decisões políticas tendo por meta esse desenvolvimento. Seu discurso tentava mudar o comportamento do rei e da corte portuguesa, que naquele momento histórico não demonstravam grande interesse pelo Brasil, no tocante ao papel que tinham que desempenhar, a saber: lutar em prol do engrandecimento do reino de Portugal e também da Igreja. Se o reino de Portugal, uma nação católica, prosperasse e se tornasse uma potência político-econômica entre as nações colonizadoras do século XVII (Espanha, França, Inglaterra e Holanda), então a Igreja também prosperaria. O motivo dessa relação é o pacto Igreja-Estado que naquele momento histórico estava em vigor e regia as relações políticas no Ocidente.

Por fim, afirma-se que o Padre Antônio Vieira, em seu discurso, enfatiza a importância da coroa portuguesa investir na colonização do Brasil, pois a partir desse investimento Portugal seria enaltecido no contexto internacional e, com isso, asseguraria que os portugueses permanecessem no centro das decisões políticas mundiais. E se Portugal, uma nação católica, era o centro das decisões políticas a Igreja, por conseguinte, seria o centro das decisões religiosas.

23 VIEIRA, A. Sermões. V. 1. op., cit, p. 38. 


\section{Bibliografia}

BOSI, A. Dialética da colonização. São Paulo: Companhia das Letras, 1995. BOSI, A. História concisa da literatura brasileira. 32 ed. São Paulo: Cultrix, 1994.

CERQUEIRA, L. A. A filosofia medieval como fonte da filosofia brasileira. In: Ágora Filosófica, Recife, jul/dez, 2001, p. 169-187.

COSTA, J. B. A. P. F. O milenearismo nacionalista do Padre Antônio Vieira. Associação Civil Santa Maria das Vitórias: Anápolis, 2008. Disponível em http://www.santamariadasvitorias.com.br. Acessado em 06/10/2009.

FAIRCLOUGH, N. Discurso e mudança social. Brasília: Editora da UNB, 2001.

HERMAM, V. O Padre Antônio Vieira e os problemas econômicos do império português. In: Revista Eclesiástica Brasileira, fasc. 211, setembro, 1993, p. 565-595.

MASSIMI, M. Dimensões pedagógicas e psicológicas da retórica segundo padre Antônio Vieira e a tradição jesuíta. In: Communio, Revista Internacional de Cultura, V. XXVIII, n. 3, jul./set. 2009, p. 877-892.

MEKSENAS, P. Educação, política e militância no jesuíta Antônio Vieira. In: Revista Educação em Questão, maio/ago, 2007, p. 49-72.

MOISÉS, M. A literatura portuguesa através dos textos. 29 ed. São Paulo: Cultrix, 2004.

MOISÉS, M. A literatura portuguesa. 25 ed. São Paulo: Cultrix, 1998.

MOISÉS, M. História da literatura brasileira: origem, barroco, arcadismo. V. 1.4 ed. São Paulo: Cultrix, 1997.

PÉCORA, A. Teatro do sacramento: a unidade teológico-retórico-política dos sermões de Antônio Vieira. São Paulo: UNICAMP, 1994.

VIEIRA, A. Sermões. V. 1. Erechin: Edelbra, 1998.

VIEIRA, A. Sermões. São Paulo: Hedra, 2000.

Recebido em: 11/04/2015

Aprovado em: 05/05/2015 